Revista Universo Contábil, ISSN 1809-3337

FURB, v. 7, n. 2, p. 45-64, abr./jun., 2011

doi:10.4270/ruc.2011212

Disponível em www.furb.br/universocontabil

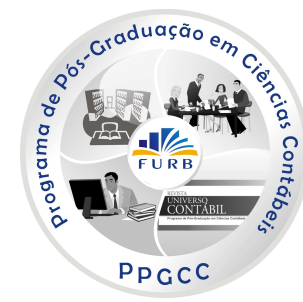

DETERMINAÇÕES DE REFAZIMENTO/REPUBLICAÇÃO DE DEMONSTRAÇÕES

FINANCEIRAS PELA CVM: O PAPEL DOS AUDITORES INDEPENDENTES'

\title{
RESTATEMENTS OF FINANCIAL REPORTS DETERMINED BY THE CVM: THE ROLE OF THE INDEPENDENT AUDITORS
}

José Alves Dantas

Doutorando do Programa Multiinstitucional e Inter-Regional de Pós-Graduação em Ciências Contábeis da UnB/UFPB/UFRN Endereço: Quadra 105, Lote 8, Apto. 501 CEP: 71915-520 - Águas Claras/DF - Brasil

E-mail: alves.dantas@bcb.gov.br Telefone: (61) 3435-9896

Simone de Mesquita Teixeira Chaves Especialização em Auditoria e Perícia Contábil no Centro Universitário Euro-Americana Bacharel em Ciências Contábeis pelo Centro Universitário do Distrito Federal

Endereço: SQS 215, Bloco A, Apto. 603 CEP: 70294-010 - Brasília/DF - Brasil

E-mail: simonetex@brturbo.com.br Telefone: (61) 3245.7242

Michela Rodrigues da Silva Especialização em Auditoria e Perícia Contábil no Centro Universitário Euro-Americana Endereço: QMSW 5, Lote 8, Bloco 3, Apto. 373, Sudoeste CEP: 70680-500 - Brasília/DF - Brasília E-mail: michela.bsb@gmail.com Telefone: (61) 3343-8978

Roberto Pires de Carvalho Especialização em Auditoria e Perícia Contábil na Centro Universitário Euro-Americana Endereço: SBS Quadra 1 - Bloco A - Lote 31, Ed.Sede I - 19.Andar - Asa Sul

CEP: 70073-900 - Brasília/DF - Brasília E-mail: robertopc@superig.com.br Telefone: (61) 3310-5302

1 Artigo recebido em 14.08.2010. Revisado por pares em 28.09.2010. Reformulado em 28.10.2010. Recomendado para publicação em 03.11.2010 por Ilse Maria Beuren (Editora). Publicado em 30.06.2011. Organização responsável pelo periódico: FURB. 


\section{RESUMO}

Com o fim de obter elementos que permitam a formulação de características médias que expliquem o padrão das ocorrências de refazimento/republicação de demonstrações financeiras, determinadas pela CVM, bem como, e mais especificamente, avaliar o papel desempenhado pelos auditores independentes nessas situações, foi realizada pesquisa descritiva com aplicação de procedimentos técnicos de natureza documental, examinando-se os 28 casos verificados entre 2001 e 2009. Os resultados dos testes demonstraram: concentração desses casos na segunda metade do período examinado; predominância de problemas nas ITRs, principalmente nos últimos exercícios; distribuição relativamente uniforme no período dos casos de refazimento das DFPs; maior número de questionamentos em relação a demonstrações auditadas pela Deloitte Touche Tohmatsu; os motivos alegados pela CVM para o refazimento concentram-se, essencialmente, em relação a impropriedades no reconhecimento e/ou mensuração de ativos e passivos e a deficiências ou ausência de disclosure em notas explicativas; o grau de antecipação dos problemas por parte dos auditores independentes pode ser considerado como relativamente pequeno - apenas em cerca de um quarto das ITRs e metade das DFPs foram emitidos parecer de auditoria com ressalva ou parágrafo de ênfase. Em relação aos motivos que deram origem às determinações de refazimento, pouco menos da metade das questões abordadas pela CVM tinham sido ressalvadas ou recebido ênfase pelos auditores independentes.

Palavras-chave: Refazimento. Demonstrações financeiras. Auditoria. Auditores. CVM.

\section{ABSTRACT}

With the purpose of finding elements which allow modeling average characteristics that explain the pattern of the events of financial reports restatements determined by the CVM, as well as, more specifically, to evaluate the independent auditors' role in such situation, a descriptive research was performed using technical procedures of documental nature, examining the 28 cases occurred between 2001 and 2009. The tests results showed: concentration of the cases in the second half of the period investigated; predominance of problems in the Quarterly Information (ITR), especially in the last years of the study; relatively uniform distribution of Financial Statements (DFP) restatement cases in the period; a larger number of cases related to financial statements audited by Deloitte Touche Tohmatsu; reasons alleged by the CVM for restatements are mainly in relation to inappropriate recognition and/or measurement of assets and liabilities and the deficiency or lack of disclosure in explanatory notes; the problems anticipation degree by independent auditors might be considered as relatively small - auditors issued qualified opinion in only about one quarter of the ITRs and half of DFPs. Regarding the reasons that led to restatements, just under half of the issues addressed by the CVM received qualified opinion by independent auditors.

Keywords: Restatement. Financial statements. Audit. Auditors. CVM.

\section{INTRODUÇÃO}

A divulgação de informações financeiras pelas companhias de modo a permitir que os investidores compreendam adequadamente a posição financeira, os resultados gerados e os riscos envolvidos em cada empresa, se constitui em requisito fundamental de funcionamento dos mercados de capitais. É um instrumento de redução da assimetria entre os administradores e os acionistas, em especial os minoritários. 
Para garantir que essa evidenciação seja apropriada e justa, os órgãos reguladores assumem papel relevante, no sentido de disciplinar o processo de divulgação, especificando o que, como e quando divulgar. No Brasil, por força das Leis n. ${ }^{\circ}$ s 6.385, de 7.12.1976, e 6.404, de 15.12.1976, esse papel é desempenhado pela Comissão de Valores Mobiliários (CVM), que disciplinou, por meio da Deliberação n. ${ }^{\circ} 488$, de 3.10.2005, o processo de apresentação de demonstrações contábeis de uso geral, a fim de assegurar a comparação tanto com os relatórios de períodos anteriores quanto com as informações de outras companhias. Essa Deliberação, que aprovou a Norma e Pronunciamento de Contabilidade (NPC) $\mathrm{n}^{\mathrm{o}} 27$ do Instituto dos Auditores Independentes do Brasil (IBRACON), foi revogada por meio da Deliberação CVM n ${ }^{\circ}$ 595, de 15.9.2009, que referendou o Pronunciamento Técnico $\mathrm{n}^{\circ} 26$ do Comitê de Pronunciamentos Contábeis (CPC), que trata da apresentação das demonstrações contábeis.

Essas demonstrações devem fornecer aos mais variados usuários informações sobre a posição patrimonial e financeira, o resultado e o fluxo financeiro das entidades, auxiliando-os em seu processo de tomada de decisão. No limite, ao identificar problemas no disclosure por parte das companhias, a CVM, no exercício de seu papel fiscalizador, pode determinar o refazimento e a republicação das demonstrações financeiras.

Considerando que, de acordo com o que prevê o art. 177, § $3^{\circ}$, da Lei n. ${ }^{\circ} 6.404 / 76$ (em redação dada na Lei ${ }^{\circ}$ 11.941, de 27.5.2009), as demonstrações financeiras devem, além de observar as normas expedidas pela CVM, ser, obrigatoriamente, submetidas à revisão por auditores independentes. Situações extremas de determinação de refazimento e republicação deveriam, ao menos em tese, ser evitadas pela ação desses profissionais, responsáveis por atestar a fidedignidade das informações produzidas pela administração e o atendimento às previsões legais e normativas, em particular aos princípios contábeis.

O presente estudo objetiva efetuar um mapeamento analítico dos casos de refazimento e republicação de demonstrações financeiras determinados pela CVM, durante o período de 2001 a 2009, cujos dados são publicados na página da entidade na internet. Esse mapeamento contempla os seguintes aspectos: análise da evolução temporal dessas determinações, buscando avaliar se há mudança de comportamento ao longo do tempo; identificação dos tipos de documentos questionados e das razões que determinaram essa situação extrema, procurando verificar quais demonstrações são mais comumente rejeitadas pelo órgão regulador e quais são os motivos mais recorrentemente destacados como causa para essa conclusão; e avaliação do papel desempenhado pelos auditores independentes nesses casos.

O pressuposto é que esse mapeamento analítico contribui para a compreensão dos eventuais problemas na elaboração das demonstrações financeiras das empresas integrantes do mercado de capitais brasileiro, bem como das eventuais responsabilidades dos auditores nesse processo.

Além desta parte introdutória, o estudo contempla nas seções subsequentes: referencial teórico sobre o tema, com destaque para a utilidade da informação contábil para o funcionamento do mercado de capitais e o papel da auditoria independente para assegurar a confiabilidade das demonstrações financeiras (Seção 2); especificação da metodologia utilizada para os testes empíricos (Seção 3); apuração e análise dos dados (Seção 4); e conclusões do estudo (Seção 5), tendo por referência a associação entre a fundamentação teórica e os dados empíricos apurados.

\section{REFERENCIAL TEÓRICO}

Pelos propósitos delineados para o estudo, a revisão da literatura busca destacar aspectos teóricos que dêem suporte aos exames empíricos, contemplando discussões sobre: a utilidade da informação contábil para o funcionamento do mercado de capitais, incluindo os impactos relacionados à assimetria verificada entre os seus participantes; o papel 
desempenhado pela auditoria no sentido de avaliar a qualidade e a confiabilidade da informação, bem como na redução da assimetria entre os agentes; e a atuação do órgão regulador, no caso a CVM, no sentido de determinar o refazimento e a republicação das demonstrações financeiras, quando relevantemente enganosas.

\subsection{Utilidade da informação contábil para o funcionamento do mercado de capitais}

Em qualquer área do conhecimento, a informação é um instrumento de grande relevância. No campo dos negócios, onde se destacam as informações de natureza contábil, quem as detém e as utiliza adequadamente adquire um diferencial competitivo em relação aos concorrentes. Cassaro (1988, apud FREITAS et al., 2009) afirma que tanto mais dinâmica será uma empresa, quanto melhores e mais adequadas forem as informações de que os usuários dispõem para as suas tomadas de decisões.

No mercado de capitais, maior usuário da informação contábil, por intermédio dos seus principais atores - empresas, investidores, corretoras, seguradoras, bancos de investimentos, analistas, entre outros - é um assunto sobre o qual todos se debruçam continuamente. Por essa razão, segundo Lopes (2002), o papel da informação contábil nos mercados financeiros é uma das áreas mais estudadas na academia.

Tratando especificamente do processo de divulgação das informações contábeis, Dantas et al. (2005) destacam que o papel desempenhado pela evidenciação ou disclosure está diretamente relacionado aos objetivos da Contabilidade, que é prover informações úteis para a tomada de decisões por parte dos usuários. $\mathrm{O}$ argumento é que, para que as demonstrações adquiram a característica da utilidade, devem conter as informações necessárias para uma adequada interpretação da situação econômico-financeira da entidade.

Niyama e Gomes (1996), por sua vez, evidenciam o alcance da divulgação, ao afirmarem que disclosure refere-se à qualidade das informações no âmbito econômicofinanceiro de uma empresa sob o ponto de vista de sua realidade operacional, dos seus recursos e obrigações e que tenham utilidade àqueles que, de forma direta ou indireta, tenham interesse nelas para acompanhar, a partir do conhecimento dos empreendimentos passados e de perspectivas quanto ao futuro, a evolução patrimonial da empresa e influenciar sua tomada de decisão.

A utilidade da informação contábil para o funcionamento do mercado de capitais pode ser depreendida das afirmações de Verrechia (2001), ao estabelecer os pressupostos em que se sustenta a teoria da divulgação e que influenciam a precificação dos ativos, tais como: os investidores são diversamente informados; os investidores fazem inferências racionais dos preços de mercado; os investidores antecipam racionalmente a divulgação; os investidores são informados com qualidade diversa e heterogênea; os investidores interpretam a divulgação de maneira diferenciada; os investidores agregam opiniões diversas, ou seja, alguns agentes incorporam a divulgação nas suas expectativas posteriores; e os investidores condicionam as suas opiniões de acordo com estímulos econômicos diversos, ou seja, eles fazem inferências racionais tanto para preços de mercado quanto para volume de transações.

Ainda conforme Verrechia (2001), a teoria da divulgação está baseada em três dimensões: na associação, ao investigar a reação dos usuários às informações divulgadas; no julgamento, ao procurar identificar como os usuários tomam decisões e as empresas decidem divulgar ou não certa informação; e na eficiência, ao verificar quais padrões de divulgação são preteridos.

Nesse contexto, a informação contábil assume papel relevante no mercado de capitais, pois sua divulgação tem como pilares a qualidade, a transparência e a tempestividade dos dados apresentados, fornecendo aos usuários condições para avaliar os riscos e o desempenho dos negócios da empresa de forma a passar confiança aos investidores (LOPES, 2002). 
Como contraponto a esses requisitos de qualidade, transparência e tempestividade na divulgação financeira surge o fenômeno da assimetria da informação, considerado como o cenário em que uma das partes envolvidas num processo econômico possui conhecimento diferente das outras partes, podendo deter maiores ou menores informações, dependendo da posição que esse usuário ocupar em determinada situação (DOWNES; GOODMAN, 2003). É o caso do acionista controlador de uma empresa, sob a influência de quem as demonstrações contábeis são preparadas, assumir uma posição privilegiada ao obter maiores informações em detrimento da outra parte, ou seja, o acionista investidor.

Niyama e Silva (2008) entendem que a assimetria ocorre pelo fato de a informação ter adquirido tanta importância que passou a ser tratada como um bem econômico. Com isso, a empresa, a quem cabe a produção e a divulgação da informação de forma quase exclusiva, pode limitar o acesso a ela, caso não exista normatização específica para este fim. Nesse sentido, a assimetria tende a impactar de modo negativo o mercado de capitais, com a falta de confiabilidade e de transparência, que são pontos fundamentais para a realização das negociações. Isso leva os órgãos competentes a elaborarem normas reguladoras e fiscalizadoras para obrigar a divulgação do mínimo necessário para a tomada de decisão dos investidores.

Em se configurando a assimetria da informação, o favorecimento que uma das partes do processo detém pode ser utilizado em proveito próprio e, consequentemente, em detrimento das demais. Para exemplificar, Niyama e Silva (2008) usam a situação em que o controlador pode ter conhecimento, antes da divulgação para os interessados, de que o resultado da empresa foi acima do esperado e, assim, utilizar-se disso para adquirir mais ações da companhia. Também pode tentar manipular os resultados e, no caso de sucesso, torna-se difícil aos outros investidores determinar a confiabilidade da informação. Na mesma vertente, destaca-se a situação em que a empresa fornece informações de modo resumido ou então em excesso, não dando condições para que o usuário possa se posicionar quanto a sua tomada de decisão. Em razão desse ambiente de incerteza, uma das consequências do processo de assimetria no ambiente informacional, conforme ressalta Moerman (2009), é o impacto no custo de capital das empresas.

$\mathrm{Na}$ presença da assimetria é possível se afirmar que ficam comprometidos os requisitos destacados por Schipper (2003) para que a informação financeira possa ser útil ao processo decisório, quais sejam: deve ser relevante, ou seja, capaz de fazer diferença em um processo decisório; deve ser confiável, reportando a atividade tão adequadamente quanto possível, sendo adequadamente representada, verificável e neutra; não pode ser enviesada para atender a um resultado determinado; e deve ser comparável, evidenciando transações equivalentes similarmente e eventos distintos diferentemente.

Em síntese, é possível afirmar que a assimetria da informação compromete a utilidade da informação e pode impactar negativamente o mercado de capitais, principalmente se não forem utilizados mecanismos para sua minimização. Razão pela qual uma das linhas de pesquisa acadêmica que tem sido explorada é a relação entre a qualidade do disclosure e o nível de assimetria da informação, como em Brown e Hillegeist (2007). Nesse contexto, surge a figura dos organismos que podem contribuir para viabilizar a redução dessa assimetria.

\subsection{Papel da auditoria na redução da assimetria e na garantia da qualidade da informação}

Para Niyama e Silva (2008), relevantes mudanças vêm ocorrendo no mercado brasileiro. A existência da crescente profissionalização desse mercado e a capacitação dos agentes exigem, cada vez mais, a busca por informações de melhor qualidade para seus usuários. Esse fato ocorre devido à crescente necessidade de que as informações divulgadas sejam de alta qualidade, transparentes e tenham credibilidade. No entanto, há situações em 
que se verifica a existência de diferentes interesses entre os diversos usuários da informação, como por exemplo, entre um acionista administrador e os demais investidores, que acaba por gerar conflitos e com eles um custo, denominado custo de agência.

É nesse cenário que o papel da auditoria ganha importância e assume, dentre outras, a função de proteger o investidor, segundo Múrcia (2007), atestando a confiabilidade das informações contábeis divulgadas pelas empresas, buscando minimizar a assimetria da informação e seus impactos no mercado. É o entendimento exposto pela U.S. Chamber of Commerce (2006), para quem a missão da auditoria tem sido, historicamente, prover confiança para os investidores e garantir a padronização e a disciplina da contabilidade corporativa, aumentando a liquidez e o potencial econômico do mercado de capitais.

Posicionamento equivalente é destacado pela IFAC (2008), ao afirmar que o objetivo de uma auditoria de demonstrações financeiras é possibilitar ao auditor expressar uma opinião sobre se foram preparadas, em todos os aspectos materiais, de acordo com um framework aplicável - no caso, os padrões contábeis definidos pelos órgãos reguladores. As normas profissionais exigem a apresentação de um relatório ou parecer, com a opinião imparcial e independente sobre o resultado da revisão efetuada, o que pode ser considerado, conforme Santos e Grateron (2003), como a prestação de contas do auditor. Merchant e Van der Stede (2007) também ressaltam que em uma auditoria financeira, os auditores externos são responsáveis por expressar uma opinião sobre se as demonstrações financeiras preparadas pela administração são apresentadas de forma justa, de acordo com os princípios contábeis geralmente aceitos.

Ao discutir a essência dos padrões de contabilidade, Hendriksen e Van Breda (1999) reforçam, indiretamente o papel desempenhado pelos auditores, ao afirmar que os padrões não devem ser medidos pelo seu efeito imediato sobre os indivíduos, mas em termos da criação de um sistema de informação financeira confiável, traduzida como aquele razoavelmente livre de viés e que retrata fielmente o que visa representar. Como se percebe, mesmo sem citar objetivamente o papel da auditoria, ao destacar a relevância da confiabilidade da informação como elemento central de adequação do processo de registro, avaliação e comunicação da informação contábil, os autores acabam por ressaltar, indiretamente a missão da auditoria. Esse papel de confirmar a precisão das demonstrações financeiras publicadas também é destacado por Gastineau e Kritzman (1999) como a essência do trabalho de auditoria.

Arens e Loebbecke (1996) resumem o propósito da auditoria ao associá-lo ao risco de informação por parte do usuário. Segundo os autores, esse risco reflete a possibilidade de que a informação sobre a qual se toma decisões sobre o risco empresarial não esteja correta - uma das causas seria a possibilidade de demonstrações financeiras imprecisas, que pode ser dirimida pela ação do auditor.

Nesse contexto, a auditoria é uma ferramenta necessária para a credibilidade nas atividades do mercado de capitais - condição para o fluxo normal das operações econômicas. Para esse propósito, além de outras, o Conselho Federal de Contabilidade aprovou, por meio

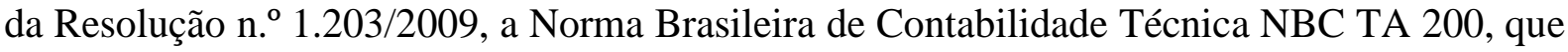
trata dos objetivos gerais do auditor independente e da condução da auditoria em conformidade com normas próprias.

A NBC TA 200 define que o objetivo da auditoria é aumentar o grau de confiança nas demonstrações contábeis por parte dos usuários. Isso é alcançado mediante a expressão de uma opinião pelo auditor sobre se as demonstrações que foram elaboradas, em todos os aspectos relevantes, em conformidade com uma estrutura de relatório financeiro aplicável. No caso da maioria das estruturas conceituais, essa opinião expressa se as demonstrações estão apresentadas adequadamente, em todos os aspectos relevantes, em conformidade com os princípios e práticas contábeis vigentes. A auditoria conduzida em conformidade com as normas e exigências éticas relevantes capacita o auditor a formar essa opinião. 
Como base para a opinião do auditor, as NBC TAs exigem que este obtenha segurança razoável de que as demonstrações contábeis como um todo estejam livres de distorção relevante, independentemente do que a tenha causado, se fraude ou erro. Asseguração razoável é um nível elevado de segurança conseguido quando o auditor obtém evidência de auditoria apropriada e suficiente para reduzir a um nível aceitável o risco de auditoria definido como o risco de que o auditor expresse uma opinião inadequada quando as demonstrações contábeis contiverem distorção relevante (IFAC, 2008). Contudo, asseguração razoável não é um nível absoluto de segurança, porque há limitações inerentes em uma auditoria que resultam do fato de que a maioria das evidências em que o auditor baseia suas conclusões e sua opinião é persuasiva e não conclusiva.

De certa forma, os usuários da informação esperam que a auditoria, por meio de seu trabalho, que resultará em pareceres e relatórios, corrija imperfeições, erros ou possíveis fraudes nas informações contidas nas demonstrações contábeis de cada empresa auditada.

O parecer do auditor independente é o documento mediante o qual o auditor expressa sua opinião, de forma clara e objetiva, sobre as demonstrações contábeis nele indicadas. Como o auditor assume, por meio do parecer, responsabilidade técnico-profissional definida, inclusive de ordem pública, é indispensável que tal documento obedeça às características intrínsecas e extrínsecas estabelecidas nas normas competentes. De acordo com a Resolução CFC no 830/98 (norma vigente à época dos casos examinados nesse estudo, revogada pela Resolução CFC n $\left.{ }^{\circ} 1.203 / 2009\right)$, em condições normais, o parecer do auditor é dirigido aos acionistas, cotistas ou sócios, ao conselho de administração ou à diretoria da entidade, devendo expressar, clara e objetivamente, se as demonstrações auditadas, em todos os aspectos relevantes, estão, em sua opinião, adequadamente representadas ou não, consoantes as disposições contidas nas normas relativas. Ainda de acordo com tal Resolução, os pareceres de auditoria são classificados da seguinte forma, conforme a situação específica:

a) parecer sem ressalva - quando o auditor conclui, sobre todos os aspectos relevantes, que as demonstrações foram preparadas de acordo com os princípios e as normas contábeis e há apropriada divulgação de todos os assuntos relevantes;

b) parecer com ressalva - quando o auditor conclui que as demonstrações apresentam adequadamente a situação patrimonial e financeira da empresa, exceto em relação a uma conta ou um grupo de contas;

c) parecer adverso - quando o auditor verifica a existência de efeitos que, isolada ou conjuntamente, foram de tal relevância que comprometem o conjunto das demonstrações; e

d) parecer com abstenção de opinião - quando há limitação na extensão do exame ou incertezas relevantes que impossibilitem o auditor de formar uma opinião.

Com a adoção das novas normas de auditoria, aprovadas pelo CFC no final de 2009, o parecer passa a ser denominado de relatório, e quanto aos tipos são definidos como "opinião não modificada ou sem modificações", "opinião com ressalvas", "opinião adversa" e "abstenção de opinião". Como se percebe, não obstante essa alteração nos termos, em relação à especificação das condições que justificam a aplicação de cada um deles, há uma correlação direta entre os tipos de pareceres e os de relatórios.

Como síntese, é possível afirmar que o auditor assume papel relevante no funcionamento do mercado de capitais, atuando no sentido de reduzir a assimetria de informações, por meio dos seus pareceres - elo entre as empresas, representadas por seus administradores, e os investidores e outros usuários, que não possuem os mesmos níveis informacionais.

Para isso, espera-se dos auditores independentes uma postura de competência e independência, que transmita confiabilidade ao mercado e que venha ao encontro dos 
fundamentos norteadores do posicionamento inicial da CVM, ao instituir as primeiras normas para o registro de auditores independentes que, segundo parágrafo introdutório da Nota Explicativa à Instrução CVM N ${ }^{0}$ 308/99, continuam válidos e atualizados. São eles: (i) a importância da auditoria independente como suporte indispensável ao órgão regulador; (ii) a figura do auditor independente como elemento imprescindível para a credibilidade do mercado e como instrumento de inestimável valor na proteção dos investidores; (iii) a exatidão e a clareza das demonstrações contábeis, inclusive a divulgação de informações indispensáveis à visualização da situação patrimonial e financeira e dos resultados da entidade auditada, dependem de um sistema de auditoria eficaz e, fundamentalmente, da tomada de consciência do auditor quanto ao seu verdadeiro papel dentro deste contexto; e (iv) a necessidade de que o mercado disponha de auditores altamente capacitados e que desfrutem de um elevado grau de independência no exercício da sua atividade.

Em resumo, é possível se afirmar que como um instrumento essencial de provimento de confiança aos investidores e demais usuários das informações contábeis divulgadas pelas organizações, a auditoria será tanto mais efetiva quanto maior for a qualidade dos trabalhos desenvolvidos. Na prática, cada vez que se constata que demonstrações financeiras foram publicadas sem atender aos requisitos de divulgação adequada, justa e plena, a utilidade dos trabalhos desenvolvidos pelos auditores é profundamente questionada.

\subsection{Justificativas para refazimento e republicação de demonstrações}

Credibilidade é fator essencial em qualquer nível de relacionamento. Em relação aos negócios e aos aspectos financeiros que os envolve, torna-se ainda mais sensível. Por isso, o mercado de valores mobiliários se vê obrigado a exigir de seus intervenientes padrões de conduta rigorosos de ética e de eficiência. Em razão de o funcionamento do mercado se fundamentar no estreito relacionamento entre os investidores e os agentes que oferecem títulos, a confiabilidade é essencial para o desenvolvimento dos negócios.

A CVM, no arcabouço das atribuições que lhe foram concedidas pela legislação, possui poderes normativos e punitivos. Os primeiros visam regular a atuação dos diversos agentes, enquanto os segundos possibilitam a punição daqueles que praticarem atos em desacordo com as normas e regulamentos. Na ocorrência de eventual deficiência informativa, esta é imediatamente comunicada, mediante ofício de notificação, à companhia com a determinação de elaborar as correções necessárias de erros ou inconsistências, e fazer a devida republicação do documento correspondente. Dentre as atribuições da CVM, existe, ainda, a de fiscalizar a publicação dos relatórios trimestrais e anuais.

A partir de 2001, a Deliberação CVM n $388 / 2001$ permite que o conteúdo dos ofícios de notificação seja divulgado de modo a viabilizar aos investidores e ao publico em geral conhecer as causas que motivaram a determinação do refazimento/republicação das demonstrações financeiras dessas empresas. A divulgação do inteiro teor desses ofícios é feita pela CVM em seu sitio eletrônico, sendo essa ação fundamental para a realização do presente estudo.

Segundo determina a Resolução $\mathrm{CFC} \mathrm{n}^{\circ}$ 737/92, a determinação para republicação das demonstrações contábeis é cabível quando as que tenham sido divulgadas apresentem erros e/ou quando informações de caráter relevante para seu perfeito entendimento tenham sido classificadas como insuficientes ou não tenham sido divulgadas. Múrcia (2007) destaca a importância e o alcance dessa Norma, ao afirmar que não obstante o arcabouço jurídico que normatiza a forma de apresentação das demonstrações no mercado interno, há empresas que acabam omitindo ou distorcendo informações sobre sua situação econômico-financeira.

Dadas as suas características, esse tipo de evento - a identificação de distorções relevantes nas demonstrações financeiras e a determinação de seu refazimento e republicação - tem sido objeto de pesquisas que procuram identificar o contexto em que ocorreram e as 
consequências econômicas de sua ocorrência, como, por exemplo, em Richardson, Tuna e Wu (2002), Palmrose, Richardson e Scholz (2004) e Plumlee e Yohn (2009). No Brasil, no entanto, segundo Múrcia e Borba (2005), o tema "republicação" ainda é pouco divulgado e estudado, ao contrário do que ocorre no cenário internacional.

\section{METODOLOGIA DA PESQUISA}

Com o propósito de promover um mapeamento analítico sobre os casos de refazimento e republicação de demonstrações financeiras determinados pela CVM, e de acordo com os parâmetros definidos por Gil (1999), a pesquisa é classificada, quanto aos objetivos, como descritiva, por buscar descrever características do fenômeno, a partir do exame, do registro, da análise, classificação e da interpretação dos dados.

Quanto aos procedimentos técnicos utilizados, conforme Gil (1999) a pesquisa é definida como documental, por procurar organizar informações sobre os casos de determinações de refazimento e republicação de demonstrações financeiras, aplicando-lhes um tratamento analítico.

O estudo contempla os 28 casos de determinação de refazimento e republicação de demonstrações financeiras, por parte da CVM, entre os anos de 2001 e 2009, identificados por meio dos ofícios correspondentes, cujos teores são disponibilizados na página do órgão na rede mundial de computadores. Cabe ressaltar que a consideração do estudo a partir de 2001 se deve ao fato de que somente naquele ano, com a publicação da Deliberação CVM n ${ }^{\circ}$ $388 / 2001$, foi permitida a divulgação dos conteúdos dos ofícios com as causas que motivaram a determinação do refazimento/republicação das demonstrações financeiras.

Considerando os objetivos do estudo, os dados foram segregados e analisados de acordo com os seguintes parâmetros: data da determinação; período-base da demonstração a ser refeita e republicada; tipo de documento a ser corrigido; empresa de auditoria responsável pelo exame da demonstração questionada; motivo da determinação de refazimento e republicação; tipo de parecer emitido pelos auditores independentes em relação ao documento questionado e aos motivos alegados para o refazimento.

Pretende-se, com essa avaliação analítica, obter elementos que permitam a formulação de características médias que expliquem o padrão desse tipo de ocorrência, bem como, e mais especificamente, avaliar o papel desempenhado pelos auditores independentes em situações do gênero.

\section{ANÁLISE DOS DADOS}

A organização e a análise dos dados referentes aos 28 casos de determinação de refazimento e republicação de demonstrações financeiras foram feitas de forma a possibilitar a abordagem do fenômeno estudado, de acordo com os parâmetros especificados no capítulo 3 , da maneira como segue.

\subsection{De acordo com a data da determinação e o período-base da demonstração}

O primeiro parâmetro de análise utilizado é a verificação da evolução dos casos de determinações de refazimento e republicação ao longo do tempo, considerando a data da deliberação pela CVM (entenda-se ano de expedição do ofício com a determinação) e a data de referência da demonstração questionada (leia-se exercício social a que se reporta a determinação). Os resultados são demonstrados na Tabela 1, ressaltando-se que, em relação à data-base das demonstrações, o total é diferente do número de deliberações, tendo em vista que uma mesma deliberação pode se referir à necessidade de refazimento e republicação de mais de um documento e/ou abranger mais de um exercício. 
Tabela 1 - Distribuição dos casos de determinação de refazimento/republicação de 2001 a 2009, de acordo com a data da deliberação e a data-base da demonstração

\begin{tabular}{|c|c|c|c|c|c|}
\hline \multicolumn{3}{|c|}{ Por data da deliberação } & \multicolumn{3}{|c|}{ Por data-base da demonstração } \\
\hline Ano & Quantidade & Percentual & Ano & Quantidade & Percentual \\
\hline & & & Antes 2000 & 2 & $3.1 \%$ \\
\hline 2001 & 3 & $10.7 \%$ & 2000 & 4 & $6.1 \%$ \\
\hline 2002 & 3 & $10.7 \%$ & 2001 & 6 & $9.2 \%$ \\
\hline 2003 & 1 & $3.6 \%$ & 2002 & 4 & $6.1 \%$ \\
\hline 2004 & 0 & $0.0 \%$ & 2003 & 0 & $0.0 \%$ \\
\hline 2005 & 0 & $0.0 \%$ & 2004 & 1 & $1.5 \%$ \\
\hline 2006 & 6 & $21.4 \%$ & 2005 & 8 & $12.3 \%$ \\
\hline 2007 & 2 & $7.1 \%$ & 2006 & 16 & $24.6 \%$ \\
\hline 2008 & 9 & $32.1 \%$ & 2007 & 9 & $13.8 \%$ \\
\hline 2009 & 4 & $14.3 \%$ & 2008 & 15 & $23.1 \%$ \\
\hline Total & 28 & $100.0 \%$ & Total & 65 & $100.0 \%$ \\
\hline
\end{tabular}

Fonte: elaborada a partir dos dados extraídos do sítio da CVM.

A distribuição dos dados de acordo com a data da deliberação revela que o maior número de determinações para refazimento e republicação ocorreu nos quatro últimos anos, 2006 a 2009, que respondem por 74,9\% dos casos, com destaque para o ano de 2008, em que foram verificadas nove deliberações, $32,1 \%$ do total. Outros fatos relevantes são que nos anos de 2004 e 2005 não houve qualquer determinação para refazimento e republicação, e que no ano de 2003 houve apenas uma ocorrência dessa natureza. Não obstante essa concentração maior nos últimos anos da série, não é possível se fazer inferências sobre esse comportamento, tendo em vista a tendência não ser uniforme e o número de elementos analisados (28) ser demasiado reduzido para se avaliar as tendências estatísticas.

Em relação à data-base das demonstrações questionadas, a análise dos dados demonstra que há uma concentração de determinações de refazimento e republicação nos exercícios sociais de 2005 a 2008, correspondendo a 73,9\% do total, com destaque para os exercícios sociais de 2006, com 16 casos, e de 2008, com 15 casos, que respondem por 47,7\% do total de ocorrências.

Em síntese, os dados demonstram uma concentração de eventos de determinação de refazimento em republicação na segunda metade do período examinado, tanto se for considerada a data da deliberação quanto a data-base da demonstração questionada.

\subsection{De acordo com o tipo de documento a ser corrigido}

Nos termos das orientações contidas no Ofício-Circular/CVM/SEP n. ${ }^{\circ} 1 / 2005$, as demonstrações financeiras, elaboradas nos termos do art. 176 da n. ${ }^{\circ}$ Lei 6.404/76, deverão ser apresentadas, acompanhadas do relatório da administração e do parecer do auditor independente, conforme estabelece a Instrução CVM n. ${ }^{\circ}$ 202/93 e suas alterações. Tais demonstrações incluem a apresentação de informações periódicas e eventuais, entre elas:

a) Informações Trimestrais (ITR) - inclui demonstrações financeiras (balanço patrimonial, demonstração de resultados e demonstração de alterações na posição financeira, juntamente com as notas relacionadas), além de, normalmente, uma visão narrativa das operações comerciais. Não é exigida no quarto trimestre, quando suas informações são incluídas no formulário DFP, com informações do exercício social completo. São acompanhadas de relatório de revisão especial, emitido por auditor independente; 
b) Demonstrações Financeiras Padronizadas (DFP) - são compostas de Balanço Patrimonial, Demonstração do Resultado do Exercício, Demonstração da Mutação do Patrimônio Líquido, Parecer dos Auditores Independentes, Relatório da Administração e Notas Explicativas; e

c) Informações Anuais (IAN) - documento contábil de periodicidade anual que inclui, além do resumo das principais contas de demonstrações financeiras da empresa, dados sobre a estrutura societária, e outras informações relevantes sobre as atividades operacionais da mesma.

Como adendo, cabe ressaltar que essas exigências da Instrução CVM n. ${ }^{\circ}$ 202/93 perduraram durante o período objeto do estudo, sendo revogada pela Instrução CVM n. ${ }^{\circ}$ 480/2009, que, entre outras alterações, cria o Formulário Cadastral (FC) e substitui o formulário IAN pelo Formulário de Referência (FR).

Com o fim de identificar em quais tipos de documento é mais comum a ocorrência de problemas que resultaram nas deliberações da CVM para refazimento e republicação, os elementos da amostra foram distribuídos de acordo com o tipo de documento a ser corrigido. O resultado dessa análise é consolidado na Tabela 2.

Tabela 2 - Distribuição dos casos de determinação de refazimento/republicação de 2001 a 2009, de acordo com o tipo de documento a ser corrigido

\begin{tabular}{|c|c|c|c|c|c|c|c|c|c|c|c|c|}
\hline \multirow{2}{*}{$\begin{array}{l}\text { Docu- } \\
\text { mento }\end{array}$} & \multicolumn{10}{|c|}{ Data-base do documento a ser refeito e republicado } & \multirow{2}{*}{ Soma } & \multirow{2}{*}{ Perc. } \\
\hline & 1995 & 1999 & 2000 & 2001 & 2002 & 2004 & 2005 & 2006 & 2007 & 2008 & & \\
\hline ITR & 0 & 0 & 0 & 2 & 3 & 0 & 3 & 13 & 7 & 15 & 43 & $66,1 \%$ \\
\hline DFP & 1 & 1 & 4 & 3 & 1 & 1 & 4 & 2 & 1 & 0 & 18 & $27,7 \%$ \\
\hline IAN & 0 & 0 & 0 & 1 & 0 & 0 & 1 & 1 & 1 & 0 & 4 & $6,2 \%$ \\
\hline TOTAL & 1 & 1 & 4 & 6 & 4 & 1 & 8 & 16 & 9 & 15 & 65 & $100 \%$ \\
\hline
\end{tabular}

Fonte: elaborada a partir dos dados extraídos dos Ofícios de Notificação expedidos pela CVM.

Os dados demonstram haver uma maior concentração de problemas que resultaram em determinação de refazimento e republicação nas ITRs, respondendo por $66,1 \%$ das ocorrências verificadas no período do estudo. As DFPs apresentam um percentual menor, embora não menos relevante, de documentos a serem refeitos, correspondendo a $27,7 \%$ do total. As IANs foram as que apresentaram a menor incidência de problemas, com 6,2\% apenas quatro dos 65 documentos questionados pela CVM.

Outra evidência é que os casos de refazimento e republicação das ITRs se concentram, essencialmente nos três últimos exercícios (35 de um total de 43), enquanto os questionamentos em relação às DFPs são distribuídos de maneira relativamente uniforme ao longo dos anos, não havendo concentrações mais relevantes. Isso parece indicar uma maior preocupação do órgão regulador com as ITRs nos últimos anos.

\subsection{De acordo com a empresa de auditoria responsável pelo exame}

Nessa seção, os 28 casos de determinação de refazimento e republicação de demonstrações são analisados em relação à empresa de auditoria responsável pelos exames, no intuito de identificar o eventual grau de concentração em algumas das firmas de auditoria, conforme demonstrado na Tabela 3. 
Tabela 3 - Distribuição dos casos de determinação de refazimento/republicação de 2001 a 2009, de acordo com a empresa de auditoria responsável pelo exame

\begin{tabular}{|c|c|c|}
\hline Empresa de Auditoria & Quantidade & Percentual \\
\hline Deloitte Touche Tohmatsu Auditoria Independente & 8 & $28,5 \%$ \\
\hline Pricewaterhousecoopers Auditoria Independente S/C & 4 & $14,3 \%$ \\
\hline Arthur Andersen & 3 & $10,7 \%$ \\
\hline KPMG Auditores Independentes & 3 & $10,7 \%$ \\
\hline BDO Directa Auditores & 2 & $7,1 \%$ \\
\hline BDO Trevisan Auditores Independentes & 2 & $7,1 \%$ \\
\hline Audimar Auditores Independentes & 1 & $3,6 \%$ \\
\hline ETAE Auditores Independentes & 1 & $3,6 \%$ \\
\hline IMER Puerari e Cia Auditores & 1 & $3,6 \%$ \\
\hline INA Instituto Nacional de Auditores & 1 & $3,6 \%$ \\
\hline Terco Grant Thornton Auditores Independentes S/C & 1 & $3,6 \%$ \\
\hline Não identificada (caso da Acesita) & 1 & $3,6 \%$ \\
\hline Total & 28 & $100.0 \%$ \\
\hline
\end{tabular}

Fonte: elaborada a partir dos dados extraídos do sítio da CVM.

Os dados evidenciam que as auditorias nas demonstrações questionadas pela CVM durante o período objeto do estudo foram realizadas por 11 empresas diferentes. A Deloitte Touche Tohmatsu foi a firma responsável pelos exames do maior número de demonstrações com determinação de refazimento e republicação, respondendo por oito das 28 deliberações, o que representa $28,5 \%$ do total. A Pricewaterhousecoopers, com quatro auditorias, e a Arthur Andersen e a KPMG, com três auditorias, cada uma, foram responsáveis por outros $35,7 \%$ das auditorias realizadas. As demais empresas realizaram entre uma e duas auditorias, cada.

O maior número de casos relacionados a cada empresa de auditoria tem correlação, obviamente, com a quantidade de clientes dessas empresas. Ou seja, é natural que as grandes firmas apresentem maior número de documentos questionados. Como os exames não abrangeram a participação relativa desses casos em relação ao número de clientes de cada firma de auditoria, não é possível se fazer afirmações conclusivas sobre o grau de recorrência de problemas relacionados às empresas responsáveis pelos exames.

De qualquer forma, alguns fatos chamam a atenção: (i) o número de demonstrações a serem refeitas e republicadas auditadas pela Deloitte Touche Tohmatsu se diferencia do de outras empresas de auditoria de porte equivalente, como a Pricewaterhousecoopers e a KPMG; (ii) a Arthur Andersen, embora tenha descontinuado suas operações desde 2002, registra o mesmo número de demonstrações questionadas que a KPMG - em atividade durante todo o período; e (iii) nenhuma das demonstrações questionadas pela CVM foi auditada pela Ernest \& Young, empresa de auditoria de grande porte, o que poderia justificar o registro de números semelhantes ao de outras de tamanho equivalente, como a KPMG, a Pricewaterhousecoopers e a Deloitte Touche Tohmatsu.

\subsection{De acordo com o motivo alegado para o refazimento/republicação}

Para o propósito de identificar os motivos que deram suporte às determinações, por parte da CVM, de refazimento e republicação de DFPs, ITRs e/ou IANs, os 29 diferentes argumentos expostos pelo órgão regulador nos ofícios de notificação expedidos foram divididos em cinco grupos, conforme sintetizado no Quadro 1. 
Quadro 1 - Motivos determinantes para as deliberações de refazimento/republicação de demonstrações

\begin{tabular}{|c|c|}
\hline Agrupamento & Motivos detalhados nos ofícios de notificação \\
\hline $\begin{array}{l}\text { Impropriedades no } \\
\text { reconhecimento e/ou } \\
\text { mensuração de ativos e } \\
\text { passivos }\end{array}$ & $\begin{array}{l}\text { Não provisão ou subestimação de contingências ou reconhecimento indevido de } \\
\text { ativo contingente; inadequação na divulgação dos créditos tributários; inadequação } \\
\text { nos registros de incorporações - ágio; incorreção no cálculo ou não contabilização } \\
\text { de tributos; incorreção nas informações do ativo imobilizado - reavaliação; } \\
\text { inadequação na apuração ou classificação dos investimentos ou operações com } \\
\text { coligadas; incorreção na avaliação de ativo permanente; não constituição de } \\
\text { provisão para perdas; não aplicação do teste de recuperabilidade de ativos; e } \\
\text { impropriedades em relação às informações quantitativas e valor justo dos } \\
\text { instrumentos financeiros derivativos. }\end{array}$ \\
\hline $\begin{array}{l}\text { Impropriedades no } \\
\text { reconhecimento e/ou } \\
\text { registro de contas de }\end{array}$ & $\begin{array}{l}\text { Valores não transitados pelo resultado; e classificação indevida de despesas } \\
\text { operacionais. }\end{array}$ \\
\hline $\begin{array}{l}\text { Deficiência ou ausência } \\
\text { de disclosure em notas } \\
\text { explicativas }\end{array}$ & $\begin{array}{l}\text { Notas explicativas fora dos padrões ou insatisfatórias; ausência de nota explicativa } \\
\text { de critérios de avaliação de elementos patrimoniais; ausência de nota explicativa em } \\
\text { relação a impostos sobre ativos e passivos; ausência de nota explicativa em relação a } \\
\text { arrendamento mercantil; ausência de nota explicativa de critérios para constituição } \\
\text { de PCLD; ausência ou insuficiência de nota explicativa para imobilizado; ausência } \\
\text { de nota explicativa para empréstimos financeiros; ausência de nota explicativa sobre } \\
\text { remuneração da administração; notas explicativas não satisfatórias em relação às } \\
\text { principais práticas contábeis no que se refere ao diferido, devedores duvidosos, } \\
\text { aplicações financeiras, investimentos, etc; ausência de nota explicativa sobre partes } \\
\text { relacionadas; e ausência de clareza nas notas explicativas relativas às informações } \\
\text { dos instrumentos financeiros derivativos. }\end{array}$ \\
\hline $\begin{array}{l}\text { Inobservância a } \\
\text { princípios contábeis }\end{array}$ & $\begin{array}{l}\text { Não aplicação do princípio de competência; e inobservância aos preceitos do } \\
\text { conservadorismo e da objetividade. }\end{array}$ \\
\hline Problemas gerais & $\begin{array}{l}\text { Relatório de administração fora dos padrões; problemas na classificação na DMPL; } \\
\text { demonstrações consolidadas não satisfatórias; e retenção indevida de lucros - não } \\
\text { aprovacão do orçamento de capital. }\end{array}$ \\
\hline
\end{tabular}

Fonte: elaborado a partir dos dados extraídos do sítio da CVM.

Tendo por referência o agrupamento exposto no Quadro 1, os motivos elencados nos ofícios emitidos pela CVM foram sintetizados na Tabela 4, ressaltando que o total de motivos alegados pela CVM difere do total de deliberações e do total de documentos questionados (Tabelas 1, 2 e 3), pelas seguintes razões: uma deliberação pode determinar o refazimento de mais de um documento e alegar diferentes motivos; um mesmo motivo pode ser a causa para o refazimento de mais de um documento; e o refazimento de um documento pode ser decorrente de mais de um motivo.

Tabela 4 - Distribuição dos casos de determinação de refazimento/republicação de 2001 a 2009, de acordo com o motivo alegado pela CVM

\begin{tabular}{lcc}
\hline \multicolumn{1}{c}{ Agrupamentos de motivos } & Quantidade & Percentual \\
\hline Impropriedades no reconhecimento e/ou mensuração de ativos e passivos & 35 & $45,4 \%$ \\
Deficiência ou ausência de disclosure em notas explicativas & 30 & $39,0 \%$ \\
Impropriedades no reconhecimento e/ou registro de contas de resultado & 6 & $7,8 \%$ \\
Problemas gerais & 4 & $5,2 \%$ \\
Inobservância a princípios contábeis & 2 & $2,6 \%$ \\
\hline \multicolumn{1}{c}{ Total } & 77 & $100.0 \%$ \\
\hline
\end{tabular}

Fonte: elaborada a partir dos dados extraídos do sítio da CVM.

O mapeamento aponta que os motivos mais alegados pela CVM para determinar o refazimento e republicação das demonstrações foram os relacionados a impropriedades no 
reconhecimento e/ou mensuração de ativos e passivos, com 35 casos, 45,4\% do total. Dos motivos elencados no Quadro 1 como constitutivos desse agrupamento, os que apresentaram maior incidência foram: as impropriedades em relação às informações quantitativas e valor justo dos instrumentos financeiros derivativos, com onze ocorrências; a inadequação na divulgação de créditos tributários; com quatro relatos; a inadequação na apuração ou classificação dos investimentos ou operações com coligadas, com quatro citações; e a não provisão ou subestimação de contingências ou reconhecimento indevido de ativo contingente, com três ocorrências. Desses motivos mais citados percebe-se uma prevalência de aspectos relacionados a estimativas contábeis, que envolvem, em tese, características de subjetividade, dando margem a manipulações/gerenciamento dos resultados.

$\mathrm{O}$ segundo grupo mais relevante de motivos é o relacionado à deficiência ou à ausência de disclosure em notas explicativas, com 30 casos, 39,0\% do total. Entre os motivos mais recorrentes, destacam-se: a ausência de clareza nas notas explicativas relativas às informações dos instrumentos financeiros derivativos, com onze ocorrências; as notas explicativas fora dos padrões ou insatisfatórias, com três citações; a ausência ou insuficiência de nota explicativa para imobilizado, com três relatos; e a ausência de nota explicativa sobre partes relacionadas, também com três ocorrências. Nesse grupo, os motivos elencados pela CVM para a determinação de refazimento e republicação das demonstrações têm relação direta com a falta de transparência em determinadas questões, notadamente sobre os esclarecimentos para a adoção de certos procedimentos contábeis.

Cabe ressaltar, especialmente, o fato de que tanto no grupo dos motivos relacionados a impropriedades no reconhecimento e/ou mensuração de ativos e passivos, quanto no dos argumentos vinculados a deficiência ou ausência de disclosure em notas explicativas, o problema mais citado se refere aos instrumentos financeiros derivativos. No primeiro caso, em razão de impropriedades nas informações quantitativas e valor justo, e no segundo caso pela ausência de clareza nas notas explicativas.

Os motivos relacionados aos grupos vinculados a impropriedades no reconhecimento e/ou registro de contas de resultado, a problemas gerais e a inobservância a princípios contábeis, com seis, quatro e duas ocorrências, respectivamente, respondendo, no conjunto, por $15,6 \%$ do total. Do ponto de vista analítico, o maior destaque é a constatação de quatro casos em que a CVM questiona o fato de valores não terem transitado pelo resultado.

Do exame desses motivos citados pelo órgão regulador para determinar o refazimento e a republicação de demonstrações, se verifica, de uma forma geral, tratar-se de aspectos que, em tese, devem ser identificados pelo auditor independente. É esperado desses profissionais, portanto, a adoção de providências para se evitar esse tipo de ocorrência ou o adequado reporte, em seu parecer.

\subsection{Atuação dos auditores independentes}

Nas seções 4.1 a 4.4 foi promovido o mapeamento de características dos casos de refazimento e republicação de demonstrações, determinados pela CVM. Para o atendimento ao principal objetivo do presente estudo, que é avaliar o papel desempenhado pelos auditores independentes nesses casos, é incorporada a análise das informações dos pareceres de auditoria - a parte visível dos trabalhos dos auditores independentes.

Para esse fim, inicialmente foi promovido o cotejamento entre os tipos de documentos questionados pela CVM e os tipos de pareceres emitidos pelos auditores independentes. $\mathrm{O}$ resultado é evidenciado na Tabela 5, ressaltando-se que para os efeitos do presente estudo, foram considerados como parecer com ressalva os casos em que o auditor destaca em parágrafo de ênfase o problema reportado posteriormente pela CVM. O propósito é procurar ressaltar os eventos que foram, de certa forma, antecipados pelos auditores. 
Tabela 5 - Cotejamento entre tipos de documentos objetos de determinação de refazimento e republicação e os tipos de parecer dos auditores independentes

\begin{tabular}{|c|c|c|c|c|c|c|}
\hline \multirow{2}{*}{ Tipo de Parecer de Auditoria } & \multicolumn{2}{|c|}{ ITR } & \multicolumn{2}{|c|}{ DFP } & \multicolumn{2}{|c|}{ IAN } \\
\hline & Quant. & Perc. & Quant. & Perc. & Quant. & Perc. \\
\hline Parecer com ressalva & 10 & $23.3 \%$ & 10 & $55.6 \%$ & 0 & $0.0 \%$ \\
\hline Parecer sem ressalva & 18 & $41.9 \%$ & 8 & $44.4 \%$ & 0 & $0.0 \%$ \\
\hline Parecer adverso & 0 & $0.0 \%$ & 0 & $0.0 \%$ & 0 & $0.0 \%$ \\
\hline Parecer com abstenção de opinião & 0 & $0.0 \%$ & 0 & $0.0 \%$ & 0 & $0.0 \%$ \\
\hline Sem parecer & 15 & $34.9 \%$ & 0 & $0.0 \%$ & 4 & $100.0 \%$ \\
\hline Total & 43 & $100.0 \%$ & 18 & $100.0 \%$ & 4 & $100.0 \%$ \\
\hline
\end{tabular}

Fonte: elaborada a partir dos dados extraídos do sítio da CVM.

Com o destaque preliminar de que a não apresentação de parecer de auditoria para as IANs é justificada, tendo em vista que, dada a natureza de suas informações, não há previsão de exame por parte dos auditores independentes, os dados demonstrados na Tabela 5 permitem as seguintes constatações:

a) os casos de não apresentação de parecer de auditoria se concentram nas ITRs, faltando opinião dos auditores para 34,9\% das demonstrações questionadas. Em relação às DFPs, para todas elas consta parecer de auditoria;

b) apenas $23,3 \%$ das ITRs objeto de determinação de refazimento receberam parecer de auditoria com ressalvas, o que indicaria a antecipação dos auditores na identificação dos problemas posteriormente destacados pelo órgão regulador e fiscalizador. No caso das DFPs, embora represente pouco mais da metade das demonstrações questionadas, $55,6 \%$, a proporção é bem superior ao verificado nas informações trimestrais;

c) não há casos de apresentação de parecer adverso ou com abstenção de opinião.

A combinação desses elementos permite a constatação de que o grau de antecipação dos problemas por parte dos auditores pode ser considerado como relativamente pequeno cerca de um quarto das ITRs e metade das DFPs. Além disso, pode indicar um maior zelo profissional das empresas e dos auditores na elaboração e no exame das demonstrações financeiras padronizadas, quando comparado com as informações trimestrais, tendo em vista os casos de não apresentação de parecer de auditoria para quase 35\% das ITRs e a maior proporção de relato dos problemas nas DFPs.

Cabe ressaltar, adicionalmente, que considerando a decisão da CVM de determinar o refazimento das demonstrações, mesmo a apresentação de parecer com ressalvas ou parágrafo de ênfase não seria o apropriado para a situação. Se devem ser refeitas, é porque na visão do órgão estão substancialmente comprometidas, o que exigiria parecer adverso.

Para o aprofundamento da análise sobre a atuação dos auditores, o passo seguinte consistiu em realizar o cotejamento entre os motivos destacados pela CVM para determinar o refazimento e a republicação das demonstrações e os posicionamentos dos auditores, por meio de parecer. A Tabela 6 apresenta a consolidação desse cotejamento. 
Tabela 6 - Cotejamento entre motivos destacados pela CVM para determinação de refazimento e republicação e os tipos de parecer dos auditores independentes

\begin{tabular}{lcccc}
\hline \multicolumn{1}{c}{ Agrupamentos de motivos } & $\begin{array}{c}\text { Com } \\
\text { ressalva }\end{array}$ & $\begin{array}{c}\text { Sem } \\
\text { ressalva }\end{array}$ & $\begin{array}{c}\text { Sem } \\
\text { parecer }\end{array}$ & Total \\
\hline $\begin{array}{l}\text { Impropriedades no reconhecimento e/ou mensuração de ativos } \\
\text { e passivos }\end{array}$ & 15 & 18 & 2 & 35 \\
\hline Deficiência ou ausência de disclosure em notas explicativas & $15.9 \%$ & $51.4 \%$ & $5.7 \%$ & $100.0 \%$ \\
\hline Impropriedades no reconhecimento e/ou registro de contas de & $50.0 \%$ & $30.0 \%$ & $20.0 \%$ & $100.0 \%$ \\
\hline resultado & 4 & 1 & 1 & 6 \\
\hline Problemas gerais & $66.7 \%$ & $16.7 \%$ & $16.7 \%$ & $100.0 \%$ \\
\hline Inobservância a princípios contábeis & 3 & 0 & 1 & 4 \\
\hline \multirow{2}{*}{ Total } & $75.0 \%$ & $0.0 \%$ & $25.0 \%$ & $100.0 \%$ \\
\hline
\end{tabular}

Fonte: elaborada a partir dos dados extraídos do sítio da CVM.

Da análise desses dados merecem destaque as seguintes constatações:

a) menos da metade, 49,4\%, dos motivos alegados pela CVM para determinar o refazimento e a republicação das demonstrações mereceram ressalva ou parágrafo de ênfase pelos auditores independentes;

b) os motivos mais recorrentes para a necessidade de refazimento e republicação de demonstrações - impropriedades no reconhecimento e/ou mensuração de ativos e passivos - foram exatamente aqueles em que os auditores menos se anteciparam ao posicionamento da CVM, emitindo parecer com ressalvas ou ao menos tratando a questão em parágrafo de ênfase em apenas $42,9 \%$ dos motivos destacados pelo órgão regulador;

c) no caso do outro agrupamento de motivos com número de ocorrências mais relevante - deficiência ou ausência de disclosure em notas explicativas - os auditores emitiram parecer com ressalva ou parágrafo de ênfase em relação à metade, $50 \%$, dos motivos alegados pelo órgão fiscalizador para determinar o refazimento e republicação das demonstrações.

Em síntese, os dados referentes ao cotejamento entre os motivos para as determinações de refazimento e as opiniões dos auditores revelaram uma situação equivalente à constatada ao se examinar os documentos, ou seja, o grau de antecipação dos problemas por parte da auditoria independente é relativamente baixa - pouco menos da metade - mesmo ignorandose o fato de que a ressalva ou o parágrafo de ênfase não seria o suficiente para situações do gênero. Esse problema é mais acentuado nos casos de impropriedades no reconhecimento e/ou mensuração de ativos e passivos.

\section{CONCLUSÃO}

O presente estudo teve por objetivo analisar os casos de refazimento e republicação de demonstrações financeiras determinados pela CVM, no período de 2001 a 2009, com o fim de identificar: como tem sido a evolução temporal desses casos; quais são os documentos mais questionados; que motivos determinantes dessa situação extrema são mais recorrentes; e qual o papel desempenhado pelos auditores independentes nessas situações. 
Em relação à evolução temporal, os resultados dos exames demonstraram uma concentração de casos de determinação de refazimento e republicação na segunda metade do período examinado, tanto se considerarmos a data da deliberação, pela CVM, quanto à database da demonstração questionada.

Quanto aos tipos de documentos, constatou-se que as ITRs são os mais questionados pelo órgão regulador, respondendo por cerca de dois terços do total, seguido das DFPs com menos de $30 \%$ dos casos. Ficou evidenciado, também, que os problemas nas ITRs se concentraram fortemente nos três últimos exercícios, enquanto os questionamentos em relação às DFPs são distribuídos de maneira relativamente uniforme ao longo dos anos, não havendo concentrações mais relevantes, o que pode ser indício de uma maior preocupação do órgão regulador em relação às informações trimestrais.

Uma possível razão para uma maior concentração de casos nos últimos exercícios e nas ITRs pode ser explicado por eventos pontuais no ambiente regulatório, que demandam certo tempo para que as empresas de capital aberto e as firmas de auditoria independentes possam a eles se adequar. Podem ser consideradas como exemplo as mudanças introduzidas pela Deliberação CVM n. ${ }^{\circ}$ 550/08, que passaram a ser aplicadas às ITRs referentes aos trimestres encerrados a partir de 30 de setembro de 2008. Nesse período houve um aumento relevante no número de ITRs objeto de determinação de refazimento.

No tocante às firmas de auditoria responsáveis pelos exames das demonstrações questionadas pela CVM, verificou-se que a Deloitte Touche Tohmatsu responde pelo maior número de documentos a serem refeitos e republicados. Outros dois fatos merecem destaque: o número de documentos de responsabilidade da Arthur Andersen, não obstante sua descontinuidade desde 2002; e a inexistência de documentos de responsabilidade de uma das maiores empresas de auditoria, a Ernest \& Young, ao contrário das demais big four.

O mapeamento dos motivos alegados pela CVM para determinar o refazimento e republicação das demonstrações revelou que os relacionados a impropriedades no reconhecimento e/ou mensuração de ativos e passivos e a deficiência ou ausência de disclosure em notas explicativas respondem por cerca de $85 \%$ dos casos. Na maioria dos motivos citados pela CVM, prevalecem aspectos relacionados a estimativas contábeis, que envolvem características de subjetividade, e à falta de transparência em determinadas questões, notadamente os esclarecimentos para a adoção de certos procedimentos contábeis.

Particularmente em relação à atuação dos auditores independentes nesses casos, os exames demonstraram que o grau de antecipação dos problemas por parte dos auditores pode ser considerado como relativamente pequeno, tendo em vista que: (i) em relação aos documentos questionados, apenas em cerca de um quarto das ITRs e metade das DFPs foram emitidos parecer com ressalva ou parágrafo de ênfase; e (ii) em relação aos motivos que deram origem às determinações de refazimento, pouco menos da metade das questões abordadas pela CVM tinham sido ressalvadas ou recebido ênfase pelos auditores independentes.

Mesmo esse desempenho considerado relativamente insatisfatório dos auditores em reportar antecipadamente os problemas utilizados como argumentos pela CVM para deliberar pelo refazimento e republicação das demonstrações só é alcançado desconsiderando-se o fato de que a apresentação de parecer com ressalvas ou parágrafo de ênfase não seria o apropriado para a situação. Se devem ser refeitas, é porque na visão do órgão estão substancialmente comprometidas, o que exigiria um parecer adverso.

Outro fato importante a se destacar é que há indícios de um maior zelo profissional das empresas e dos auditores na elaboração e no exame das demonstrações financeiras padronizadas, quando comparado com as informações trimestrais, tendo em vista: os casos de não apresentação de parecer de auditoria para quase 35\% das ITRs; e a maior proporção de relato, por parte dos auditores, dos problemas nas DFPs. 
Como limitações, o presente estudo não apresenta elementos suficientes para se fazer inferências sobre o comportamento das empresas que divulgam suas demonstrações, das firmas de auditoria ou do mercado, tendo em vista o pequeno número de incidência de casos de determinações de refazimento e republicação, o que dificulta a realização de estimativas estatísticas.

Também há que se ressaltar que o estudo não avança em relação aos eventuais questionamentos que podem ser formalizados em relação à decisão da CVM para refazer e republicar as demonstrações. Considerando que a deliberação pode ser reformulada, os dados apontados podem sofrer modificações.

\section{REFERÊNCIAS}

ARENS, Alvin A.; LOEBBECKE, James K. Auditoria: un enfoque integral. 6. ed. México: Prentice Hall, 1996.

BRASIL. Lei n. ${ }^{\circ}$ 6.385, de 7 de dezembro de 1976. Dispõe sobre o mercado de valores mobiliários e cria a Comissão de Valores Mobiliários. Texto compilado e consolidado. Disponível em: 〈http://www.planalto.gov.br/ccivil_03/Leis/L6385.htm〉. Acesso em: 30 jul. 2010.

BRASIL. Lei n. ${ }^{\circ}$ 6.404, de 15 de dezembro de 1976. Dispõe sobre as Sociedades por Ações. Texto compilado e consolidado. Disponível em: <http://www.planalto.gov.br/ccivil_03/ Leis/L6404consol.htm>. Acesso em: 30 jul. 2010.

BROWN, Stephen; HILLEGEIST, Stephen A. How disclosure quality affects the level of information asymmetry. January, 2007. SSRN Working Paper Series. Disponível em: <http://papers.ssrn.com/sol3/papers.cfm?abstract_id=956256>. Acesso em: 2 out. 2010.

COMISSÃO DE VALORES MOBILIÁRIOS (CVM). Instrução CVM $\mathbf{n}^{\mathbf{0}} \mathbf{2 0 2}$, de 6 de dezembro de 1993. Dispõe sobre o registro de companhia para negociação de seus valores mobiliários em Bolsa de Valores ou no mercado de balcão. Disponível em: <http://www.cvm.gov.br>. Acesso em: 22 fev. 2010.

COMISSÃO DE VALORES MOBILIÁRIOS (CVM). Deliberação CVM n⿳o 388, de 2 de maio de 2001. Delega competência à Superintendência de Relações com Empresas para dar divulgação às determinações de refazer e republicar as Demonstrações Financeiras e as Informações Trimestrais de Companhias Abertas. Disponível em: 〈http://www.cvm.gov.br〉. Acesso em: 30 nov. 2009.

COMISSÃO DE VALORES MOBILIÁRIOS (CVM). Deliberação CVM n⿳⺈ 488, de 3 de outubro de 2005. Aprova o Pronunciamento do IBRACON NPC $\mathrm{n}^{\circ} 27$ sobre Demonstrações Contábeis - Apresentação e Divulgações. Disponível em: <http://www.cvm.gov.br>. Acesso em: 30 nov. 2009.

COMISSÃO DE VALORES MOBILIÁRIOS (CVM). Deliberação CVM no 550, de 17 de outubro de 2008. Dispõe sobre a apresentação de informações sobre instrumentos financeiros derivativos em nota explicativa às informações trimestrais - ITR. Disponível em: <http://www.cvm.gov.br>. Acesso em: 20 fev. 2010.

COMISSÃO DE VALORES MOBILIÁRIOS (CVM). Deliberação CVM no 595, de 15 de setembro de 2009. Aprova o Pronunciamento Técnico CPC 26 do Comitê de Pronunciamentos Contábeis, que trata da apresentação das demonstrações contábeis. Disponível em: 〈http://www.cvm.gov.br>. Acesso em: 1 out. 2010.

COMISSÃO DE VALORES MOBILIÁRIOS (CVM). Instrução CVM n⿳⺈ 480, de 7 dezembro de 2009. Dispõe sobre o registro de emissores de valores mobiliários admitidos à 
negociação em mercados regulamentados de valores mobiliários. Disponível em: <http://www.cvm.gov.br>. Acesso em: 22 fev. 2010.

COMISSÃO DE VALORES MOBILIÁRIOS (CVM). Nota Explicativa à Instrução CVM $\mathbf{n}^{\mathbf{0}}$ 308, de 14 de maio de 1999. Dispõe sobre o registro e o exercício da atividade de auditoria independente no âmbito do mercado de valores mobiliários, define os deveres e as responsabilidades dos administradores das entidades auditadas no relacionamento com os auditores independentes. Disponível em: 〈http://www.cvm.gov.br〉. Acesso em: 22 fev. 2010.

CONSELHO FEDERAL DE CONTABILIDADE (CFC). Resolução CFC n. ${ }^{\mathbf{7 3 7}}$, de 27 de novembro de 1992. Aprova a NBC T 6 - Da Divulgação das Demonstrações Contábeis. 6.1 Da Forma de Apresentação. 6.2 - Do Conteúdo das Notas Explicativas. 6.3 - Das Republicações. Disponível em: <http://www.cfc.org.br>. Acesso em: 3 dez. 2009.

CONSELHO FEDERAL DE CONTABILIDADE (CFC). Resolução n. ${ }^{\mathbf{1}} \mathbf{1 . 2 0 3}$, de 27 de novembro de 2009. Aprova a NBC TA 200 - Objetivos Gerais do Auditor Independente e a Condução da Auditoria em Conformidade com Normas de Auditoria. Disponível em: <http://www.cfc.org.br>. Acesso em: 3 dez. 2009.

DANTAS, José Alves; ZENDERSKY, Humberto Carlos; SANTOS, Sérgio Carlos dos; NIYAMA, Jorge Katsumi. A dualidade entre os benefícios do disclosure e a relutância das organizações em aumentar o grau de evidenciação. Revista Economia \& Gestão. Belo Horizonte, v. 5, n. 11, p. 56-76, dez. 2005.

DOWNES, John; GOODMAN, Jordan E. Dictionary of finance and investment terms. 6 ed. New York: Barron's, 2003.

FREITAS, Antonio de Souza; SIMMI, Santa Secilia Ferreira; ZANETTE, Mariane; RIBAS, Daiane. A importância da informação contábil no processo de tomada de decisão. Revista Contábil e Empresarial Fiscolegis, 9 jul. 2009. Disponível em: <http://www.netlegis.com.br>. Acesso em: 25 jan. 2010.

GASTINEAU, Gary L.; KRITZMAN, Mark P. Dicionário de administração de risco financeiro. São Paulo: BMF, 1999.

GIL, Antônio C. Métodos e técnicas de pesquisa social. 5 ed. São Paulo: Atlas, 1999.

HENDRIKSEN, Eldon S; VAN BREDA, Michael F. Teoria da contabilidade. Atlas: São Paulo, 1999.

INTERNATIONAL FEDERATION OF ACCOUNTANTS (IFAC). Handbook of International Auditing, Assurance, and Ethics Pronouncements. New York: IFAC, 2008.

LOPES, Alexsandro Broedel. A informação contábil e o mercado de capitais. São Paulo: Pioneira/Thomson Learning, 2002.

MERCHANT, Kenneth A.; VAN DER STEDE, Wim A. Management control systems. 2 ed. Harlow: Pearson, 2007.

MOERMAN, Regina W. The impact of information asymmetry on debt pricing and maturity. November, 2009. SSRN Working Paper Series. Disponível em: <http://papers.ssrn.com/sol3/papers.cfm?abstract_id=1152863>. Acesso em: 2 out. 2010.

MURCIA, Fernando Dal-Ri. Relevância dos red flags na detecção dos riscos de fraudes nas demonstrações contábeis: a percepção de auditores independentes brasileiros. 2007. Dissertação (Mestrado em Ciências Contábeis) - Universidade Federal de Santa Catarina, Florianópolis, 2007.

MURCIA, Fernando Dal-Ri; BORBA, José Alonso. Quantificando as fraudes contábeis sob 
duas óticas: jornais econômicos versus periódicos acadêmicos no período de 2001-2004. Cadernos de Controladoria - Controladoria Geral do Município do Rio de Janeiro. Disponível em: <http://www7.rio.rj.gov.br/cgm/academia/ artigos/arquivos/2005/01.pdf>. Acesso em: 27 abr. 2010.

NIYAMA, Jorge Katsumi; GOMES, Amaro L. Oliveira. Contribuição ao aperfeiçoamento dos procedimentos de evidenciação contábil aplicáveis às demonstrações financeiras de bancos e instituições assemelhadas. In: CONGRESSO BRASILEIRO DE CONTABILIDADE, 15., 1996, Goiânia. Anais... Brasília: CFC, 1996.

NIYAMA, Jorge Katsumi; SILVA, César Augusto Tibúrcio. Teoria da contabilidade. São Paulo: Atlas, 2008.

PALMROSE, Zoe-Vonna; RICHARDSON, Vernon J.; SCHOLZ, Susan. Determinants of market reactions to restatement announcements. Journal of Accounting and Economics, v. 37, p. 59-89, 2004. doi:10.1016/j.jacceco.2003.06.003

PLUMLEE, Marlene; YOHN, Teri L. An analysis of the underlying causes attributed to restatements. 2009. Working Paper Series SSRN. Disponível em: <http://ssrn.com/abstrat=1104189>. Acesso em: 16 abr. 2010.

RICHARDSON, Scott; TUNA, Irem; WU, Min. Predicting earnings management: the case of earnings restatements. 2002. Working Paper Series SSRN. Disponível em: $<$ http://ssrn.com/abstrat=338681>. Acesso em: 16 abr. 2010.

SANTOS, Ariovaldo; GRATERON, Ivan R. G. Contabilidade criativa e responsabilidade dos auditores. Revista Contabilidade \& Finanças - FEA/USP, n. 32, p. 7-22, 2003.

SCHIPPER, Katherine. Principles-based accounting standards. Accounting Horizons, v. 17, n.1, p.61-72, 2003. doi:10.2308/acch.2003.17.1.61

VERRECCHIA, Robert E. Essays on disclosure. Journal of Accounting and Economics, n. 32, p. 97-180, 2001. doi:10.1016/S0165-4101(01)00025-8

U.S. CHAMBER OF COMMERCE. Auditing: a profession at risk. U.S. Chamber of Commerce. Washington, DC, January, 2006. 